\title{
Cutaneous nevi and internal cancer risk: results from two large prospective cohorts of US
}

\section{women}

Xin Li, $\mathrm{ScD}^{1,2}$; Wenting Wu, $\mathrm{PhD}^{3}$; Edward Giovannucci, MD, $\mathrm{ScD}^{4,5,6}$; Meir J. Stampfer, MD, DrPH ${ }^{4,5,6}$; Xiang Gao, $\mathrm{MD}, \mathrm{PhD}^{7}$; and Jiali Han, $\mathrm{PhD}^{1,2}$

${ }^{1}$ Department of Epidemiology, Richard M. Fairbanks School of Public Health, Indiana University, Indianapolis, IN 46202, USA;

${ }^{2}$ Indiana University Melvin and Bren Simon Cancer Center, Indianapolis, IN 46202, USA;

${ }^{3}$ Department of Medical and Molecular Genetics, Indiana University School of Medicine, Indianapolis, IN 46202, USA;

${ }^{4}$ Department of Epidemiology, Harvard T.H. Chan School of Public Health, Boston, MA 02115, USA;

${ }^{5}$ Channing Division of Network Medicine, Brigham and Women's Hospital and Harvard Medical School, Boston, MA 02115, USA;

${ }^{6}$ Department of Nutrition, Harvard T.H. Chan School of Public Health, Boston, MA 02115, USA;

${ }^{7}$ Department of Nutritional Sciences, College of Health and Human Development, Pennsylvania State University, PA 16802, USA.

\section{Corresponding author:}

Jiali Han, Ph.D

Department of Epidemiology, Richard M. Fairbanks School of Public Health, Indiana University Address: 1050 Wishard Boulevard, RG 5112, Indianapolis, IN 46202-2872

Email: jialhan@iu.edu Phone: 317-278-0370

This is the author's manuscript of the article published in final edited form as:

Li, X., Wu, W., Giovannucci, E., Stampfer, M. J., Gao, X., \& Han, J. (2020). Cutaneous nevi and internal cancer risk: Results from two large prospective cohorts of US women. International Journal of Cancer, 147(1), 14-20. https://doi.org/10.1002/ijc.32703 
Word count: 2,369

List of Abbreviations: NHS, Nurses' Health Study; NHS2, Nurses' Health Study 2; BMI, body mass index; UV, ultraviolet; HR, hazard ratio; CI, confidence interval; GH, growth hormone; IGF, insulin-like growth factor; $\mathrm{PMH}$, postmenopausal hormone; BCC, basal cell carcinoma; SCC, squamous cell carcinoma; T2D, type 2 diabetes.

Novelty and Impact: In two large prospective cohorts of US women, compared to those with no nevi on extremity, there is an increase in overall internal cancer risk among individuals with $\geq 1$ nevi in a dose-dependent trend. To the best of our knowledge, this is the first study reporting higher nevus count is associated with an increased risk of internal cancer; further investigations are needed to evaluate nevus count as a phenotypic marker of cancer risk.

Conflict of interest: The authors declare no conflict of interest. 


\section{Abstract}

Elevated cutaneous nevus number has been linked to longer telomeres. Recently, a large systematic Mendelian randomization study identified a significant positive association between telomere length and risk of cancer. Here, we hypothesized that higher nevus count, as a phenotypic marker of longer telomere, may be associated with increased risk of internal cancer, and prospectively examined the association between nevus count and total as well as site-specific cancer risk among participants in the Nurses' Health Study (NHS, 1986-2012) and the Nurses' Health Study 2 (NHS2, 1989-2013) using Cox proportional hazards models. During 3,900,264 person-years of follow-up, we documented a total of 23,004 internal cancer cases $(15,484$ in the NHS and 7,520 in the NHS2). Compared to participants who had no nevi, the multivariate hazard ratios of total cancer (excluding skin cancer) were 1.06 (95\% confidence interval $[\mathrm{CI}], 1.03-1.09)$ for women with 1-5 nevi, 1.08 (95\% CI, 1.03-1.15) for those who had 6-14 nevi, and 1.19 (95\% CI, 1.05-1.35) for those with 15 or more nevi ( $\mathrm{p}$ trend $<0.0001$ ). Moreover, because nevus count has been associated with risk of breast cancer previously, we conducted a secondary analysis by excluding breast cancer from the outcomes of interest. The results were very similar to those of our primary analysis. For individual cancer, most of the associations with nevus count were positive but not statistically significant. In conclusion, we identified the number of cutaneous nevi as a phenotypic marker associated with internal cancer risk, which may be explained by telomere biology. 


\section{Introduction}

Nevi, also referred to as moles, are benign clonal proliferations of melanocytes ${ }^{1}$. Sun exposure may be involved in nevus formation, but variation in nevus count between individuals is primarily determined by genetic factors, as shown by family and twin studies ${ }^{2-4}$.

Elevated nevus number has been associated with longer telomeres ${ }^{5,6}$. And telomere length has been implicated in cancer development ${ }^{7}$. Despite inconsistent results from observational studies ${ }^{8-12}$, a recent systematic Mendelian randomization study reported a positive association between telomere length and risk of cancer ${ }^{13}$. Their findings are generally consistent with those from previous prospective observational studies, most of which found weak positive association or null association between telomere length and total as well as site-specific cancer risk ${ }^{5,11,14-26}$. Moreover, the results are similar to those reported by several other Mendelian randomization studies on the association of telomere length with risk of lung cancer, melanoma, glioma, and chronic lymphocytic leukemia ${ }^{27-30}$.

Having a large number of nevi on sun-exposed body sites is a well-known risk factor for malignant melanoma ${ }^{31,32}$. However, limited evidence is available for the association between number of nevi and risk of internal cancer. In the current study, we hypothesized that higher nevus count, as a phenotypic marker of longer telomere, may be associated with increased internal cancer risk, and prospectively investigated this association in two large cohorts of US women.

\section{Methods}

\section{$\underline{\text { Study Population, Inclusion, and Exclusion }}$}

Our study population consisted of participants from two ongoing cohort studies: the Nurses' Health Study (NHS) and the Nurses' Health Study 2 (NHS2). The NHS is a prospective cohort study 
established in 1976 with 121,700 female U.S registered nurses who were then 30-55 years old. All of them completed and returned a mailed self-administered questionnaire about their medical histories and lifestyle at baseline. The NHS2 was established in 1989, when 116,671 female registered nurses aged 25-42 and residing in the United States at the time of enrollment responded to an initial questionnaire on their medical histories and baseline health-related exposures. In both cohorts, information regarding medical history, lifestyle, and disease diagnoses was updated every 2 years with a follow-up rate of $90 \%$.

In the present analyses, the baselines in the NHS and NHS2 were 1986 and 1989, respectively, when participants reported self-counted number of cutaneous nevi. We excluded participants diagnosed with cancer before baseline. Participants who did not report number of cutaneous nevi were excluded, as were those reporting non-white ancestry. In total, 72,726 women from the NHS and 103,766 from the NHS2 were included. The study was approved by the Institutional Review Board of Brigham and Women's hospital and the Harvard T.H. Chan School of Public Health, and those of participating registries as required.

\section{$\underline{\text { Measurements of nevus count and other covariates }}$}

In the NHS, in 1986, participants were asked to provide information on melanocytic nevus count (larger than $3 \mathrm{~mm}$ in diameter) from shoulder to wrist on left arm by choosing from the following categories: none, $1-2,3-5,6-9,10-14,15-20$, and $21+$. In the baseline questionnaire in 1989 , the NHS2 participants reported numbers of cutaneous nevi, without specification of size, on lower legs (knees to ankles, both legs) using the same categories.

Data on body mass index (BMI), smoking status, physical activity, menopausal status, use of 
postmenopausal hormones, and disease history (including heart disease, stroke, type 2 diabetes, squamous cell carcinoma, and basal cell carcinoma) was first collected at baseline and then updated biennially in subsequent questionnaires for both cohorts. Information on alcohol consumption was first asked in 1986 and 1991 in the NHS and NHS2, respectively, and then updated every four years. In 1990s, participants were asked about their location of residence (US states) at birth, age 15, and age 30 . The 50 US states were categorized into low, medium, and high ultraviolet (UV) index groups 33 and incorporated into the multivariable-adjusted models.

\section{$\underline{\text { Ascertainment of cancer cases }}$}

Participants in the NHS and NHS2 reported diagnosis of cancers every two years. With their permission, medical records were then obtained and reviewed by physicians to confirm their self-reported diagnosis. Eligible cases consisted of women with incident cancers (excluding melanoma and non-melanoma skin cancers) diagnosed any time after baseline up to the 2012 follow-up cycle in the NHS and 2013 follow-up cycle in the NHS2. Only pathologically confirmed invasive cases were included. In total, 23,004 internal cancer cases were documented $(15,484$ in the NHS and 7,520 in the NHS2).

\section{$\underline{\text { Statistical analysis }}$}

We used age-adjusted and multivariable-adjusted Cox proportional hazards models stratified by follow-up cycles and age to calculate hazard ratios (HRs) and 95\% confidence intervals (CIs) of the association between nevus count and internal cancer risk. Person-time was calculated for each participant from the date of baseline questionnaire return to the date of the first report of cancer 
diagnosis, death, or the end of follow-up, whichever came first. We grouped women into four categories based on their self-reported nevus count (none, 1-5, 6-14, and 15+) and created a continuous variable $(0,3,10$, and 15$)$ to represent the four exposure categories for the linear trend test. In the multivariate analysis, we simultaneously controlled for age, smoking status, alcohol intake, BMI, physical activity, UV index, menopausal status/postmenopausal hormone use, and history of heart disease, stroke, type 2 diabetes, squamous cell carcinoma, and basal cell carcinoma. We used the most updated information for time-varying variables prior to each follow-up interval to take into account potential changes over follow-up. Missing data during any follow-up interval were coded as a missing indicator category for categorical variables and with carried-forward values for continuous variables. Multiplicative interactions between nevus count and other covariates were tested using the likelihood ratio test comparing a "main effect only" model vs. a model with product term. All covariates in the multivariable-adjusted models were considered individually and sequentially tested for interaction. We tested the heterogeneity of the results between the two cohorts using the Q statistic and conducted a fixed-effect inverse variance-weighted meta-analysis if there was no significant difference ${ }^{34,35}$. All statistical analyses were performed using SAS software (version 9.4 for UNIX; SAS Institute, Cary, North Carolina). We considered two-sided P values less than 0.05 to be statistically significant.

\section{Data Availability}

Further information including the procedures to obtain and access data from the Nurses' Health Studies is described at https://www.nurseshealthstudy.org/researchers (contact email: nhsaccess@channing.harvard.edu). 


\section{Results}

The baseline age-standardized characteristics of participants by categories of nevus count are listed in Table 1. Compared to participants who reported having no nevi on their arms/legs, women in higher nevus count categories were less likely to be current smokers, and more likely to have personal history of basal cell carcinoma (in both cohorts), squamous cell carcinoma and type 2 diabetes (in NHS). Other characteristics were similar among groups having different numbers of cutaneous nevi.

During 3,900,264 person-years of follow-up, we documented a total of 23,004 internal cancer cases $(15,484$ in the NHS and 7,520 in the NHS2). In both cohorts, higher numbers of cutaneous nevi were associated with increased risk of cancer, though the multivariate HRs are slightly higher in the NHS compared to those in the NHS2 for women with 6-14 and 15+ nevi (Table 2). Because we did not detect significant heterogeneity between the results of the NHS and NHS2 ( $p$ for heterogeneity in trend test $=0.14$ for multivariable-adjusted model), we combined the estimates using fixed-effect inverse variance-weighted meta-analysis. Compared to participants who had no nevi, the multivariate HRs were 1.06 (95\% CI, 1.03-1.09) for women with 1-5 nevi, 1.08 (95\% CI, 1.03-1.15) for those who had 6-14 nevi, and 1.19 (95\% CI, 1.05-1.35) for those with 15 or more nevi (P for trend < 0.0001). Additionally, we did not find significant interactions between the number of nevi and other covariates in the multivariable-adjusted model after adjusting for multiple comparisons ( $\mathrm{p}$-values for interaction $>0.05$ for all covariates).

Nevus count has been associated with risk of breast cancer previously ${ }^{36}$. Thus, we conducted a secondary analysis by excluding breast cancer from the outcomes of interest. The results 
(Supplementary Table 1) were very similar to those of our primary analysis using all internal cancer sites. Moreover, we assessed the associations between nevus count and risk of developing site-specific cancers (Supplementary Table 2). We combined the results of trend tests for total and site-specific cancer of the two cohorts, and presented the HRs and 95\% CIs associated with per 5 count increase in nevus number in Figure 1. For individual cancer sites, results of bladder cancer, lymphoma, and breast cancer reached borderline significance, associations with nevus count for the remaining cancer sites were positive but not statistically significant.

\section{Discussion}

In this analysis of two large prospective cohort studies, the number of cutaneous nevi was positively associated with incidence of total internal cancer with a significant dose-response relationship. After adjusting for potential confounding factors, there was a $19 \%$ higher risk of overall cancer among participants with $\geq 15$ nevi on their limbs as compared to those without any nevi. Importantly, the association remained significant in the secondary analysis, indicating that the observed significant association was not solely driven by previously reported association between nevus count and breast cancer. The association with nevus count was nonsignificant for most of the individual cancer sites, which may be due to a lack of power. These findings suggest that nevus count may be etiologically linked to cancer development.

One potential mechanism for this association is telomere length which has been linked to both nevus count and risk of cancer. Telomeres are long hexameric (TTAGGG)n repeats at the ends of linear eukaryotic chromosomes that are shortened by each round of DNA replication ${ }^{37}$. They serve to track the number of divisions a cell has undergone and reflect the future replication potential of a 
cell ${ }^{7}$. Efforts have been made to study relationships between telomere length and cancer risk. However, the direction and magnitude of the associations found are inconsistent across observational studies, e.g., retrospective studies tend to report increased cancer risk among individuals with shorter telomeres $^{9,10,38}$, whereas more prospective studies find weak or null associations of telomere length with overall and site-specific cancer $5,8-10,16,22,23,26,39-42$. Such inconsistency may reflect reverse causation bias in the retrospective design or variation in controlling confounding effects due to shared environmental factors. To rule out the influences of these methodological issues, Haycock et al. recently conducted a systematic Mendelian randomization study with more than $1,200,000$ participants and found that increased telomere length is associated with increased risk of cancers ${ }^{13}$. This positive association is supported by known biology. Telomere length may regulate senescence process. When telomeres shorten to a critical length, the cells may enter senescence, an important tumor-suppressive mechanism ${ }^{7}$. Cells with longer telomeres have higher proliferative potential, leading to acquiring more somatic mutations ${ }^{43}$. Previous studies found that telomeres appear to be longer among people with more and larger nevi ${ }^{5,6}$. Consistent with those findings, we report increased cancer risk among women with more cutaneous nevi.

Alternatively, nevus count and cancer may be connected through growth factors, as they both positively related to adult height. Data suggested that melanocytic nevi grow more rapidly during growth hormone $(\mathrm{GH})$ therapy ${ }^{44}$. Growth hormone exerts many of its functions through insulin-like growth factor (IGF)-1, which has numerous roles, including accelerating cell proliferation and inhibiting apoptosis ${ }^{45,46}$. The GH-IGF-1 axis has been demonstrated to play a role in the development of most common cancers among Western populations ${ }^{47}$.

Our study has several strengths. First, this is a prospective cohort study with large sample size, 
long follow-up, and updated assessment of cancer diagnosis every two years. Second, we were able to control for a number of potential confounders based on detailed cohort follow-up information, and this allowed us to determine that the association between nevus count and cancer risk was independent of the confounders being considered. Third, besides primary analysis, we also tested the association of nevus count with risk of total internal cancer (excluding breast cancer) and individual cancer to better illustrate the observed positive association.

We also acknowledge several limitations. One is that nevus count in our cohorts was self-reported. However, previous studies have evaluated the validity of self-reported information on nevus counts, and the majority found substantial agreement between nevus self-counts and dermatologist counts ${ }^{48,49}$. In one study, the Spearman's correlation coefficient was 0.91 between the two measurements ${ }^{50}$. In our cohorts, the ordinal variable of nevus count is a highly significant predictor of melanoma risk ${ }^{51}$. Genome-wide association studies of nevi number using our genetic datasets revealed biologically plausible susceptibility loci for nevus count and melanoma risk, and the same loci were replicated by other independent studies ${ }^{52-54}$. In addition, we do not have information on type or size of nevi, thus could not evaluate whether the association of interest is modified by these histopathological factors. The second limitation was that we collected information on nevus count on the left arm in the NHS, while on both legs in the NHS2. Despite such difference, conclusion regarding association between nevus count and cancer risk was consistent based on cohort-specific results. And examining the limbs was suggested previously to be a practical and suitable tool for predicting whole body nevus count ${ }^{55-57}$. Thirdly, average number of nevi varies among different age groups. Studies found nevus count typically reaches its maximum between ages 30 and 50, with a slight decrease after age $50{ }^{58}$. Considering participants of the NHS (age range 
40-65 when nevus count was asked) on average are older than those of the NHS2 (age range 25-42 when nevus count was asked), natural regression of nevus may influence results in the NHS. Furthermore, our cohorts consist primarily of white, educated US women, and thus results may not be generalizable. However, such homogeneity in a study population would minimize confounding by socioeconomic status and differential access to healthcare and assure a high quality of returned data.

In conclusion, we identified the number of cutaneous nevi as a novel phenotypic marker associated with internal cancer risk. Telomere length and growth factors may contribute to this association. Further studies are needed to better assess the relationships between nevus count and individual cancer sites and to reveal the underlying mechanisms.

\section{Acknowledgements}

We are indebted to the participants in the NHS and NHS2 for their dedication to this research. We thank the following state cancer registries for their help: Alabama, Arizona, Arkansas, California, Colorado, Connecticut, Delaware, Florida, Georgia, Idaho, Illinois, Indiana, Iowa, Kentucky, Louisiana, Maine, Maryland, Massachusetts, Michigan, Nebraska, New Hampshire, New Jersey, New York, North Carolina, North Dakota, Ohio, Oklahoma, Oregon, Pennsylvania, Rhode Island, South Carolina, Tennessee, Texas, Virginia, Washington, and Wyoming. The authors assume full responsibility for analyses and interpretation of these data. This work is supported by NIH P01 CA87969, UM1 CA186107, and UM1 CA176726. Funding for Dr. Xin Li is partially provided by the Indiana University Grand Challenge Precision Health Initiative. Dr. Jiali Han is partially supported by Walther Cancer Foundation. 


\section{References}

1. Magana-Garcia M, Ackerman AB. What Are Nevus Cells? The American Journal of Dermatopathology 1990;12:93-102.

2. Bataille V, Snieder H, MacGregor AJ, Sasieni P, Spector TD. Genetics of risk factors for melanoma: an adult twin study of nevi and freckles. Journal of the National Cancer Institute 2000;92:457-63.

3. Wachsmuth RC, Turner F, Barrett JH, Gaut R, Randerson-Moor JA, Bishop DT, Bishop JAN. The effect of sun exposure in determining nevus density in UK adolescent twins. Journal of investigative dermatology 2005;124:56-62.

4. Zhu G, Montgomery GW, James MR, Trent JM, Hayward NK, Martin NG, Duffy DL. A genome-wide scan for naevus count: linkage to CDKN2A and to other chromosome regions. European Journal of Human Genetics 2007;15:94-102.

5. Han J, Qureshi AA, Prescott J, Guo Q, Ye L, Hunter DJ, De Vivo I. A prospective study of telomere length and the risk of skin cancer. Journal of Investigative Dermatology 2009;129:415-21.

6. Bataille V, Kato BS, Falchi M, Gardner J, Kimura M, Lens M, Perks U, Valdes AM, Bennett DC, Aviv A. Nevus size and number are associated with telomere length and represent potential markers of a decreased senescence in vivo. Cancer Epidemiology Biomarkers \& Prevention 2007;16:1499-502.

7. Stewart SA, Weinberg RA. Telomeres: cancer to human aging. Annu. Rev. Cell Dev. Biol. 2006;22:531-57.

8. Weischer M, Nordestgaard BG, Cawthon RM, Freiberg JJ, Tybjærg-Hansen A, Bojesen SE. Short telomere length, cancer survival, and cancer risk in 47102 individuals. Journal of the National Cancer Institute 2013:djt016.

9. Ma H, Zhou Z, Wei S, Liu Z, Pooley KA, Dunning AM, Svenson U, Roos G, Hosgood III HD, Shen M. Shortened telomere length is associated with increased risk of cancer: a meta-analysis. PloS one 2011;6:e20466.

10. Wentzensen IM, Mirabello L, Pfeiffer RM, Savage SA. The association of telomere length and cancer: a meta-analysis. Cancer Epidemiology Biomarkers \& Prevention 2011;20:1238-50.

11. Pooley KA, Sandhu MS, Tyrer J, Shah M, Driver KE, Luben RN, Bingham SA, Ponder BA, Pharoah PD, Khaw K-T. Telomere length in prospective and retrospective cancer case-control studies. Cancer research 2010;70:3170-6.

12. Hou L, Joyce BT, Gao T, Liu L, Zheng Y, Penedo FJ, Liu S, Zhang W, Bergan R, Dai Q. Blood telomere length attrition and cancer development in the normative aging study cohort. EBioMedicine 2015;2:591-6.

13. Haycock PC, Burgess S, Nounu A, Zheng J, Okoli GN, Bowden J, Wade KH, Timpson NJ, Evans DM, Willeit P. Association Between Telomere Length and Risk of Cancer and Non-Neoplastic Diseases: A Mendelian Randomization Study. JAMA Oncology.

14. Weischer M, Nordestgaard BG, Cawthon RM, Freiberg JJ, Tybjærg-Hansen A, Bojesen SE. Short telomere length, cancer survival, and cancer risk in 47102 individuals. Journal of the National Cancer Institute 2013;105:459-68.

15. Wentzensen IM, Mirabello L, Pfeiffer RM, Savage SA. The association of telomere length and cancer: a meta-analysis. Cancer Epidemiology and Prevention Biomarkers 2011;20:1238-50.

16. Seow WJ, Cawthon RM, Purdue MP, Hu W, Gao Y-T, Huang W-Y, Weinstein SJ, Ji B-T, Virtamo J, Hosgood HD. Telomere length in white blood cell DNA and lung cancer: a pooled analysis of three prospective cohorts. Cancer research 2014;74:4090-8.

17. Caini S, Raimondi S, Johansson H, De Giorgi V, Zanna I, Palli D, Gandini S. Telomere length and the 
risk of cutaneous melanoma and non-melanoma skin cancer: a review of the literature and meta-analysis. Journal of dermatological science 2015;80:168-74.

18. Campa D, Mergarten B, De Vivo I, Boutron-Ruault M-C, Racine A, Severi G, Nieters A, Katzke VA, Trichopoulou $A$, Yiannakouris $N$. Leukocyte telomere length in relation to pancreatic cancer risk: a prospective study. Cancer Epidemiology and Prevention Biomarkers 2014;23:2447-54.

19. De Vivo I, Prescott J, Wong JY, Kraft P, Hankinson SE, Hunter DJ. A prospective study of relative telomere length and postmenopausal breast cancer risk. Cancer Epidemiology and Prevention Biomarkers 2009;18:1152-6.

20. Hofmann JN, Lan Q, Cawthon R, Hosgood HD, Shuch B, Moore LE, Rothman N, Chow W-H, Purdue MP. A prospective study of leukocyte telomere length and risk of renal cell carcinoma. Cancer Epidemiology and Prevention Biomarkers 2013;22:997-1000.

21. Julin B, Shui I, Heaphy CM, Joshu CE, Meeker AK, Giovannucci E, De Vivo I, Platz EA. Circulating leukocyte telomere length and risk of overall and aggressive prostate cancer. British journal of cancer 2015;112:769.

22. Kim S, Sandler DP, Carswell G, De Roo LA, Parks CG, Cawthon R, Weinberg CR, Taylor JA. Telomere length in peripheral blood and breast cancer risk in a prospective case-cohort analysis: results from the Sister Study. Cancer Causes \& Control 2011;22:1061.

23. Lan Q, Cawthon R, Shen M, Weinstein SJ, Virtamo J, Lim U, Hosgood HD, Albanes D, Rothman N. A prospective study of telomere length measured by monochrome multiplex quantitative PCR and risk of non-Hodgkin lymphoma. Clinical Cancer Research 2009;15:7429-33.

24. McGrath M, Wong JY, Michaud D, Hunter DJ, De Vivo I. Telomere length, cigarette smoking, and bladder cancer risk in men and women. Cancer Epidemiology and Prevention Biomarkers 2007;16:815-9.

25. Shen M, Cawthon R, Rothman N, Weinstein SJ, Virtamo J, Hosgood III HD, Hu W, Lim U, Albanes D, Lan $\mathrm{Q}$. A prospective study of telomere length measured by monochrome multiplex quantitative PCR and risk of lung cancer. Lung cancer 2011;73:133-7.

26. Walcott F, Rajaraman P, Gadalla SM, Inskip PD, Purdue MP, Albanes D, Orr E, De Vivo I, Savage SA. Telomere length and risk of glioma. Cancer epidemiology 2013;37:935-8.

27. Zhang C, Doherty JA, Burgess S, Hung RJ, Lindström S, Kraft P, Gong J, Amos Cl, Sellers TA, Monteiro AN. Genetic determinants of telomere length and risk of common cancers: a Mendelian randomization study. Human molecular genetics 2015;24:5356-66.

28. Walsh KM, Codd V, Rice T, Nelson CP, Smirnov IV, McCoy LS, Hansen HM, Elhauge E, Ojha J, Francis SS. Longer genotypically-estimated leukocyte telomere length is associated with increased adult glioma risk. Oncotarget 2015;6:42468.

29. Iles MM, Bishop DT, Taylor JC, Hayward NK, Brossard M, Cust AE, Dunning AM, Lee JE, Moses EK, Akslen LA. The effect on melanoma risk of genes previously associated with telomere length. Journal of the National Cancer Institute 2014;106:dju267.

30. Ojha J, Codd V, Nelson CP, Samani NJ, Smirnov IV, Madsen NR, Hansen HM, de Smith AJ, Bracci PM, Wiencke JK. Genetic variation associated with longer telomere length increases risk of chronic lymphocytic leukemia. Cancer Epidemiology and Prevention Biomarkers 2016;25:1043-9.

31. Gandini S, Sera F, Cattaruzza MS, Pasquini P, Abeni D, Boyle P, Melchi CF. Meta-analysis of risk factors for cutaneous melanoma: I. Common and atypical naevi. European Journal of Cancer 2005;41:28-44.

32. Wei EX, Li X, Nan H. Extremity nevus count is an independent risk factor for basal cell carcinoma and melanoma, but not squamous cell carcinoma. Journal of the American Academy of Dermatology 2019;80:970-8. 
33. Qureshi AA, Laden F, Colditz GA, Hunter DJ. Geographic variation and risk of skin cancer in US women: differences between melanoma, squamous cell carcinoma, and basal cell carcinoma. Archives of internal medicine 2008;168:501-7.

34. DerSimonian R, Laird N. Meta-analysis in clinical trials. Controlled clinical trials 1986;7:177-88.

35. Takkouche B, Cadarso-Suarez C, Spiegelman D. Evaluation of old and new tests of heterogeneity in epidemiologic meta-analysis. American journal of epidemiology 1999;150:206-15.

36. Zhang $M$, Zhang $X$, Qureshi AA, Eliassen AH, Hankinson SE, Han J. Association between cutaneous nevi and breast cancer in the Nurses' Health Study: a prospective cohort study. PLoS Med 2014;11:e1001659.

37. Harley CB: Human ageing and telomeres Ciba Found Symp 1997; 211:129-39.

38. Pellatt AJ, Wolff RK, Torres - Mejia G, John EM, Herrick JS, Lundgreen A, Baumgartner KB, Giuliano $A R$, Hines LM, Fejerman L. Telomere length, telomere - related genes, and breast cancer risk: The breast cancer health disparities study. Genes, Chromosomes and Cancer 2013;52:595-609.

39. Canzian F, Mergarten B, De Vivo I, Kaaks R, Campa D. Leukocyte telomere length in relation to pancreatic cancer risk: a prospective study. Pancreatology 2014;14:S70-S1.

40. Shen M, Cawthon R, Rothman N, Weinstein SJ, Virtamo J, Hosgood HD, Hu W, Lim U, Albanes D, Lan Q. A prospective study of telomere length measured by monochrome multiplex quantitative PCR and risk of lung cancer. Lung cancer 2011;73:133-7.

41. McGrath M, Wong JY, Michaud D, Hunter DJ, De Vivo I. Telomere length, cigarette smoking, and bladder cancer risk in men and women. Cancer Epidemiology Biomarkers \& Prevention 2007;16:815-9.

42. Zee RY, Castonguay AJ, Barton NS, Buring JE. Mean telomere length and risk of incident colorectal carcinoma: a prospective, nested case-control approach. Cancer Epidemiology Biomarkers \& Prevention 2009;18:2280-2.

43. Hanahan D, Weinberg RA. Hallmarks of cancer: the next generation. cell 2011;144:646-74.

44. Malozowski S, Green L. Premature thelarche in girls after growth hormone therapy. The Journal of Pediatrics 2001;138.

45. Milazzo G, Giorgino F, Damante G, Sung C, Stampfer MR, Vigneri R, Goldfine ID, Belfiore A. Insulin receptor expression and function in human breast cancer cell lines. Cancer Research 1992;52:3924-30.

46. Ish-Shalom D, Christoffersen C, Vorwerk P, Sacerdoti-Sierra N, Shymko R, Naor D, De Meyts P. Mitogenic properties of insulin and insulin analogues mediated by the insulin receptor. Diabetologia 1997;40:S25-S31.

47. Khandwala HM, McCutcheon IE, Flyvbjerg A, Friend KE. The effects of insulin-like growth factors on tumorigenesis and neoplastic growth. Endocrine reviews 2000;21:215-44.

48. Buettner PG, Garbe C. Agreement between self-assessment of melanocytic nevi by patients and dermatologic examination. American journal of epidemiology 2000;151:72-7.

49. Little $P$, Keefe $M$, White J. Self screening for risk of melanoma: validity of self mole counting by patients in a single general practice. Bmj 1995;310:912-6.

50. Mikkilineni $R$, Weinstock MA. Is the self-counting of moles a valid method of assessing melanoma risk? Archives of dermatology 2000;136:1550-1.

51. Cho E, Rosner BA, Feskanich D, Colditz GA. Risk factors and individual probabilities of melanoma for whites. Journal of clinical oncology 2005;23:2669-75.

52. Nan H, Xu M, Zhang J, Zhang M, Kraft P, Qureshi AA, Chen C, Guo Q, Hu FB, Rimm EB. Genome-wide association study identifies nidogen 1 (NID1) as a susceptibility locus to cutaneous nevi and melanoma risk. Human molecular genetics 2011;20:2673-9.

53. Li X, Liu H, Amos Cl, Lee JE, Thomas NE, Wei Q, Han J. A PGC1 $\beta$ genetic variant associated with nevus 
count and melanoma mortality. International journal of cancer 2017;141:1066-7.

54. Duffy DL, Zhu G, Li X, Sanna M, Iles MM, Jacobs LC, Evans DM, Yazar S, Beesley J, Law MH. Novel pleiotropic risk loci for melanoma and nevus density implicate multiple biological pathways. Nature communications 2018;9:4774.

55. Gallus S, Naldi L, Carli P, La Vecchia C. Nevus count on specific anatomic sites as a predictor of total body count: a survey of 3,406 children from Italy. American journal of epidemiology 2007;166:472-8.

56. BAIN C, COLDITZ GA, WILLETT WC, STAMPFER MJ, GREEN A, BRONSTEIN BR, MIHM MC, ROSNER B, HENNEKENS CH, SPEIZER FE. Self-reports of mole counts and cutaneous malignant melanoma in women: methodological issues and risk of disease. American journal of epidemiology 1988;127:703-12.

57. Ribero S, Zugna D, Osella - Abate S, Glass D, Nathan P, Spector T, Bataille V. Prediction of high naevus count in a healthy UK population to estimate melanoma risk. British Journal of Dermatology 2016;174:312-8.

58. Stegmaier OC. Natural regression of the melanocytic nevus. Journal of Investigative Dermatology 1959;32:413-21. 
Table 1. Age-adjusted baseline characteristics according to categories of nevus count in the NHS and NHS2

\begin{tabular}{|c|c|c|c|c|c|c|c|c|}
\hline & \multicolumn{4}{|c|}{$\begin{array}{c}\text { NHS } \\
\text { (number of nevi on left arm from shoulder to wrist) }\end{array}$} & \multicolumn{4}{|c|}{$\begin{array}{c}\text { NHS2 } \\
\text { (number of nevi on both lower legs from knees to } \\
\text { ankles) }\end{array}$} \\
\hline & $\begin{array}{c}\text { None } \\
(\mathrm{n}=\mathbf{4 6 , 1 3 6 )}\end{array}$ & $\begin{array}{c}1-5 \\
(n=23,304) \\
\end{array}$ & $\begin{array}{c}6-14 \\
(n=2,643)\end{array}$ & $\begin{array}{c}>=15 \\
(n=643)\end{array}$ & $\begin{array}{c}\text { None } \\
(n=51,756)\end{array}$ & $\begin{array}{c}1-5 \\
(n=30,216) \\
\end{array}$ & $\begin{array}{c}6-14 \\
(n=12,295) \\
\end{array}$ & $\begin{array}{c}>=15 \\
(n=9,499)\end{array}$ \\
\hline Age (year) ${ }^{\mathrm{a}}$, mean $(\mathrm{SD})$ & $52.7(7.2)$ & $52.0(7.1)$ & $51.9(7.1)$ & $52.0(7.1)$ & $34.3(4.7)$ & $34.4(4.6)$ & $34.3(4.7)$ & $34.3(4.6)$ \\
\hline Body mass index $\left(\mathrm{kg} / \mathrm{m}^{2}\right)$, mean $(\mathrm{SD})$ & $25.1(4.7)$ & $25.6(5.0)$ & $26.5(5.5)$ & $26.9(5.7)$ & $24.3(5.2)$ & $24.1(5.1)$ & $23.8(4.8)$ & $23.5(4.5)$ \\
\hline Height (inch), mean (SD) & $64.4(3.1)$ & $64.5(3.2)$ & $64.7(3.0)$ & $64.9(2.5)$ & $64.9(2.6)$ & $64.9(2.6)$ & $65.0(2.6)$ & $65.2(2.6)$ \\
\hline Current smoking, $\%$ & 22.3 & 20.6 & 20.2 & 19.4 & 14.1 & 13.8 & 11.8 & 10.1 \\
\hline Alcohol intake (g/d), mean (SD) & $6.3(11.0)$ & $6.0(10.4)$ & $5.7(9.8)$ & $5.0(8.5)$ & $3.0(5.8)$ & $3.0(5.5)$ & $3.0(5.7)$ & $3.1(6.2)$ \\
\hline $\begin{array}{l}\text { Physical activity (metabolic-equivalents } \\
\text { hours/wk), mean (SD) }\end{array}$ & $14.1(20.8)$ & $13.9(20.7)$ & $13.5(19.3)$ & $14.8(24.6)$ & $25.3(37.3)$ & $24.5(35.6)$ & $24.4(36.0)$ & $24.8(36.2)$ \\
\hline \multicolumn{9}{|l|}{ Menopausal status/PMH ${ }^{\mathrm{b}}$ status } \\
\hline - Premenopausal, \% & 43.2 . & 43.3 & 44.4 & 44.9 & 97.2 & 96.8 & 97.1 & 97.1 \\
\hline - PMH never use, $\%$ & 26.2 & 25.5 & 25.1 & 21.9 & 0.2 & 0.2 & 0.2 & 0.1 \\
\hline - PMH current use, $\%$ & 14.0 & 14.5 & 14.7 & 16.0 & 0.2 & 0.2 & 0.2 & 0.2 \\
\hline - PMH past use, $\%$ & 12.4 & 12.9 & 11.9 & 14.3 & 1.8 & 2.1 & 2.1 & 2.0 \\
\hline $\begin{array}{l}\text { UV index at birth, age } 15 \text {, and age } \\
30>=7, \%\end{array}$ & 5.5 & 5.9 & 4.5 & 5.5 & 9.7 & 11.5 & 10.7 & 10.7 \\
\hline Personal history of $\mathrm{BCC}^{\mathrm{b}}$ & 4.4 & 5.6 & 7.3 & 8.0 & 0.3 & 0.4 & 0.4 & 0.5 \\
\hline Personal history of $\mathrm{SCC}^{\mathrm{b}}$ & 0.3 & 0.3 & 0.4 & 0.5 & 0.0 & 0.0 & 0.0 & 0.0 \\
\hline Personal history of $\mathrm{T} 2 \mathrm{D}^{\mathrm{b}}$ & 3.9 & 4.5 & 6.2 & 5.7 & 0.2 & 0.2 & 0.2 & 0.1 \\
\hline
\end{tabular}

NOTE: Values are means (SD) or percentages and are standardized to the age distribution of the study populations. Values of multi-level categorical variables may not sum to $100 \%$ due to rounding or missingness.

a Value is not age-adjusted;

b Abbreviation: $\mathrm{PMH}$ - postmenopausal hormone use; $\mathrm{BCC}$ - basal cell carcinoma; SCC - squamous cell carcinoma; T2D - type 2 diabetes. 
Table 2. HRs and $95 \%$ CIs for the association between nevus count and total internal cancer risk

\begin{tabular}{|c|c|c|c|c|c|}
\hline & \multicolumn{4}{|c|}{ Levels of nevus count } & \multirow[t]{2}{*}{ P for trend } \\
\hline & None & $1-5$ & 6-14 & 15 and up & \\
\hline \multicolumn{6}{|l|}{ NHS } \\
\hline Person-years & 996,663 & 503,996 & 56,378 & 13,273 & . \\
\hline No. of cases & 9,672 & 5,053 & 596 & 163 & . \\
\hline Age-adjusted HR & 1 & $1.06(1.03,1.10)$ & $1.12(1.03,1.22)$ & $1.33(1.14,1.56)$ & $<.0001$ \\
\hline Multivariate HR $^{\mathrm{a}}$ & 1 & $1.05(1.02,1.09)$ & $1.10(1.01,1.19)$ & $1.30(1.11,1.52)$ & $<.0001$ \\
\hline \multicolumn{6}{|l|}{ NHS2 } \\
\hline Person-years & $1,164,586$ & 677,135 & 275,691 & 212,542 & \\
\hline No. of cases & 3,578 & 2,269 & 923 & 750 & \\
\hline Age-adjusted HR & 1 & $1.09(1.03,1.15)$ & $1.09(1.01,1.17)$ & $1.16(1.07,1.25)$ & 0.0001 \\
\hline Multivariate $\mathrm{HR}^{\mathrm{a}}$ & 1 & $1.08(1.03,1.14)$ & $1.07(1.00,1.16)$ & $1.14(1.05,1.23)$ & 0.0011 \\
\hline \multicolumn{6}{|l|}{ Meta-analysis ${ }^{b}$} \\
\hline Person-years & $2,161,249$ & $1,181,131$ & 332,069 & 225,815 & \\
\hline No. of cases & 13,250 & 7,322 & 1,519 & 913 & \\
\hline Age-adjusted HR & 1 & $1.07(1.04,1.10)$ & $1.10(1.04,1.17)$ & $1.22(1.07,1.39)$ & $<.0001$ \\
\hline Multivariate HR & 1 & $1.06(1.03,1.09)$ & $1.08(1.03,1.15)$ & $1.19(1.05,1.35)$ & $<.0001$ \\
\hline
\end{tabular}

a Multivariate models adjusted for age, smoking status (never, past, current 1-14,15-24, or 25+ cigarettes/day), alcohol intake (no, <5.0, 5.0-9.9, 10.0-19.9, or $20.0+\mathrm{g}$ /day), body mass index $\left(<25.0,25.0-29.9,30.0-34.9\right.$, or $\left.35.0+\mathrm{kg} / \mathrm{m}^{2}\right)$, physical activity $(<3.0,3.0-8.9,9.0-17.9,18.0-26.9$ or $27.0+\mathrm{metabolic}$ equivalent hours/wk), history of heart disease (yes or no), history of stroke (yes or no), history of type 2 diabetes (yes or no), history of squamous cell carcinoma (yes or no), history of basal cell carcinoma (yes or no), menopausal status/postmenopausal hormones use (premenopausal, PMH never, PMH past, or PMH current), and states lived at birth, age 15, and age 30 (UV index $<=5,=6$, or $>=7$ );

b No significant difference were found between results of the NHS and the NHS2, p-value for heterogeneity is greater than 0.05 . 
Figure Legend

Figure 1. Multivariable-adjusted HRs and $95 \%$ CIs of per 5 count increase in nevus count for incident cancer at 15 specific sites, total internal cancer, and total internal cancer excluding breast cancer 
Supplementary Table 1. HRs and $95 \%$ CIs for the association between nevus count and total internal cancer (excluding breast cancer) risk

\begin{tabular}{|c|c|c|c|c|c|}
\hline & \multicolumn{4}{|c|}{ Levels of nevus count } & \multirow[t]{2}{*}{ P for trend } \\
\hline & None & $1-5$ & $6-14$ & 15 and up & \\
\hline \multicolumn{6}{|l|}{ NHS } \\
\hline Person-years & 937,758 & 472,459 & 52,622 & 12,220 & \\
\hline No. of cases & 6,020 & 3,114 & 351 & 97 & \\
\hline Age-adjusted HR & 1 & $1.06(1.02,1.11)$ & $1.09(0.98,1.21)$ & $1.31(1.07,1.60)$ & 0.0004 \\
\hline Multivariate $\mathrm{HR}^{\mathrm{a}}$ & 1 & $1.06(1.02,1.11)$ & $1.07(0.96,1.19)$ & $1.28(1.05,1.57)$ & 0.0018 \\
\hline \multicolumn{6}{|l|}{ NHS2 } \\
\hline Person-years & $1,136,405$ & 658,967 & 268,641 & 206,560 & \\
\hline No. of cases & 2,049 & 1,310 & 543 & 438 & \\
\hline Age-adjusted HR & 1 & $1.10(1.03,1.18)$ & $1.12(1.01,1.23)$ & $1.18(1.07,1.31)$ & 0.0005 \\
\hline Multivariate HR ${ }^{a}$ & 1 & $1.10(1.02,1.18)$ & $1.11(1.01,1.22)$ & $1.18(1.06,1.31)$ & 0.0006 \\
\hline \multicolumn{6}{|l|}{ Meta-analysis $^{\text {b }}$} \\
\hline Person-years & $2,074,163$ & $1,131,426$ & 321,263 & 218,780 & \\
\hline No. of cases & 8,069 & 4,424 & 894 & 535 & \\
\hline Age-adjusted HR & 1 & $1.07(1.04,1.12)$ & $1.10(1.03,1.19)$ & $1.21(1.10,1.33)$ & $<.0001$ \\
\hline Multivariate HR & 1 & $1.07(1.03,1.11)$ & $1.09(1.02,1.17)$ & $1.20(1.09,1.32)$ & $<.0001$ \\
\hline
\end{tabular}

a Multivariate models adjusted for age, smoking status (never, past, current 1-14,15-24, or 25+ cigarettes/day), alcohol intake (no, <5.0, 5.0-9.9, 10.0-19.9, or $20.0+\mathrm{g} /$ day), body mass index $\left(<25.0,25.0-29.9,30.0-34.9\right.$, or $\left.35.0+\mathrm{kg} / \mathrm{m}^{2}\right)$, physical activity $(<3.0,3.0-8.9,9.0-17.9,18.0-26.9$ or $27.0+\mathrm{metabolic}$ equivalent hours/wk), history of heart disease (yes or no), history of stroke (yes or no), history of type 2 diabetes (yes or no), history of squamous cell carcinoma (yes or no), history of basal cell carcinoma (yes or no), menopausal status/postmenopausal hormones use (premenopausal, $\mathrm{PMH}$ never, $\mathrm{PMH}$ past, or PMH current), and states lived at birth, age 15, and age 30 (UV index $<=5,=6$, or $>=7$ );

b No significant difference were found between results of the NHS and the NHS2, p-value for heterogeneity is greater than 0.05 . 
Supplementary Table 2. Risks of subsequent primary cancers at different sites a according to levels of nevus count in the NHS and NHS2

\begin{tabular}{|c|c|c|c|c|c|c|c|c|c|c|c|}
\hline & & \multicolumn{5}{|c|}{ NHS } & \multicolumn{5}{|c|}{ NHS2 } \\
\hline & & \multicolumn{4}{|c|}{ Levels of nevus count } & \multirow{2}{*}{$\begin{array}{l}P \text { for } \\
\text { trend }\end{array}$} & \multicolumn{4}{|c|}{ Levels of nevus count } & \multirow{2}{*}{$\begin{array}{l}P \text { for } \\
\text { trend }\end{array}$} \\
\hline & & None & $1-5$ & $6-14$ & 15 and up & & None & $1-4$ & $5-14$ & 15 and up & \\
\hline \multirow{4}{*}{ Breast cancer $^{1}$} & Person-years & 1014997 & 517422 & 58789 & 13772 & . & 1171323 & 682624 & 278852 & 216265 & . \\
\hline & No. of cases & 3652 & 1939 & 245 & 66 & . & 1529 & 959 & 380 & 312 & . \\
\hline & Age-adjusted HR & 1 & $\begin{array}{c}1.06 \\
(1.00,1.12)\end{array}$ & $\begin{array}{c}1.17 \\
(1.03,1.33)\end{array}$ & $\begin{array}{c}1.38 \\
(1.08,1.76)\end{array}$ & 0.0003 & 1 & $\begin{array}{c}1.07 \\
(0.99,1.16)\end{array}$ & $\begin{array}{c}1.04 \\
(0.93,1.17)\end{array}$ & $\begin{array}{c}1.12 \\
(0.99,1.26)\end{array}$ & 0.09 \\
\hline & Multivariate $\mathrm{HR}^{\mathrm{b}}$ & 1 & $\begin{array}{c}1.03 \\
(0.97,1.09)\end{array}$ & $\begin{array}{c}1.11 \\
(0.97,1.27)\end{array}$ & $\begin{array}{c}1.35 \\
(1.05,1.72)\end{array}$ & 0.0089 & 1 & $\begin{array}{c}1.05 \\
(0.97,1.14)\end{array}$ & $\begin{array}{c}0.99 \\
(0.88,1.11)\end{array}$ & $\begin{array}{c}1.03 \\
(0.91,1.17)\end{array}$ & 0.84 \\
\hline \multirow{4}{*}{ Lung cancer } & Person-years & 1017783 & 518912 & 58969 & 13816 & . & 1172668 & 683432 & 279169 & 216538 & . \\
\hline & No. of cases & 1184 & 531 & 68 & 15 & . & 117 & 53 & 25 & 18 & . \\
\hline & Age-adjusted HR & 1 & $\begin{array}{c}0.92 \\
(0.83,1.02)\end{array}$ & $\begin{array}{c}1.07 \\
(0.84,1.37)\end{array}$ & $\begin{array}{c}1.01 \\
(0.61,1.69)\end{array}$ & 0.77 & 1 & $\begin{array}{c}0.78 \\
(0.56,1.07)\end{array}$ & $\begin{array}{c}0.91 \\
(0.59,1.41)\end{array}$ & $\begin{array}{c}0.84 \\
(0.51,1.38)\end{array}$ & 0.49 \\
\hline & Multivariate HR & 1 & $\begin{array}{c}0.96 \\
(0.86,1.06)\end{array}$ & $\begin{array}{c}1.15 \\
(0.90,1.47)\end{array}$ & $\begin{array}{c}1.10 \\
(0.66,1.84)\end{array}$ & 0.60 & 1 & $\begin{array}{c}0.77 \\
(0.55,1.06)\end{array}$ & $\begin{array}{c}0.94 \\
(0.61,1.46)\end{array}$ & $\begin{array}{c}0.93 \\
(0.56,1.54)\end{array}$ & 0.77 \\
\hline \multirow{4}{*}{ Colorectal cancer } & Person-years & 1017666 & 518818 & 58981 & 13822 & . & 1172607 & 683389 & 279153 & 216518 & . \\
\hline & No. of cases & 933 & 504 & 48 & 14 & . & 159 & 103 & 44 & 32 & . \\
\hline & Age-adjusted HR & 1 & $\begin{array}{c}1.12 \\
(1.01,1.25)\end{array}$ & $\begin{array}{c}0.95 \\
(0.71,1.27)\end{array}$ & $\begin{array}{c}1.17 \\
(0.69,1.98)\end{array}$ & 0.34 & 1 & $\begin{array}{c}1.13 \\
(0.88,1.44)\end{array}$ & $\begin{array}{c}1.13 \\
(0.81,1.58)\end{array}$ & $\begin{array}{c}1.09 \\
(0.74,1.59)\end{array}$ & 0.52 \\
\hline & Multivariate HR & 1 & $\begin{array}{c}1.12 \\
(1.00,1.25)\end{array}$ & $\begin{array}{c}0.93 \\
(0.70,1.25)\end{array}$ & $\begin{array}{c}1.14 \\
(0.67,1.94)\end{array}$ & 0.42 & 1 & $\begin{array}{c}1.12 \\
(0.87,1.43)\end{array}$ & $\begin{array}{c}1.13 \\
(0.80,1.58)\end{array}$ & $\begin{array}{c}1.07 \\
(0.73,1.57)\end{array}$ & 0.56 \\
\hline \multirow{4}{*}{$\begin{array}{c}\text { Endometrial } \\
\text { cancer }^{2}\end{array}$} & Person-years & 1017803 & 518886 & 58976 & 13823 & . & 1172531 & 683349 & 279150 & 216513 & . \\
\hline & No. of cases & 737 & 395 & 41 & 12 & . & 228 & 153 & 44 & 38 & . \\
\hline & Age-adjusted HR & 1 & $\begin{array}{c}1.07 \\
(0.94,1.21)\end{array}$ & $\begin{array}{c}0.98 \\
(0.71,1.34)\end{array}$ & $\begin{array}{c}1.26 \\
(0.71,2.23)\end{array}$ & 0.46 & 1 & $\begin{array}{c}1.14 \\
(0.93,1.40)\end{array}$ & $\begin{array}{c}0.81 \\
(0.59,1.12)\end{array}$ & $\begin{array}{c}0.90 \\
(0.64,1.27)\end{array}$ & 0.24 \\
\hline & Multivariate HR & 1 & $\begin{array}{c}1.02 \\
(0.90,1.15)\end{array}$ & $\begin{array}{c}0.86 \\
(0.63,1.18)\end{array}$ & $\begin{array}{c}1.07 \\
(0.60,1.91)\end{array}$ & 0.70 & 1 & $\begin{array}{c}1.14 \\
(0.93,1.41)\end{array}$ & $\begin{array}{c}0.84 \\
(0.61,1.16)\end{array}$ & $\begin{array}{c}0.95 \\
(0.67,1.35)\end{array}$ & 0.41 \\
\hline Ovarian cancer $^{2}$ & Person-years & 1018149 & 519062 & 59000 & 13824 & . & 1172608 & 683380 & 279162 & 216523 & . \\
\hline
\end{tabular}




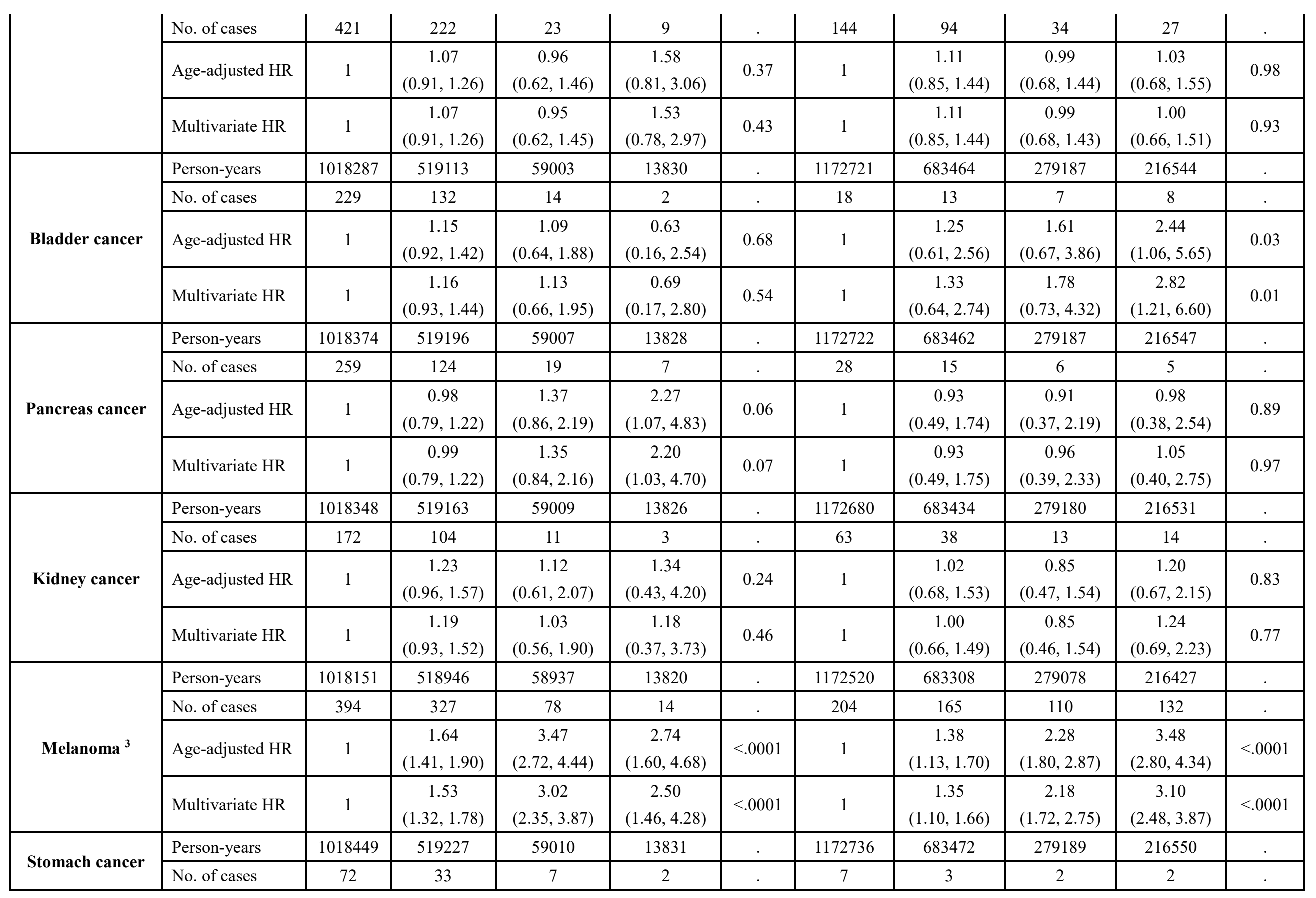




\begin{tabular}{|c|c|c|c|c|c|c|c|c|c|c|c|}
\hline & Age-adjusted HR & 1 & $\begin{array}{c}0.97 \\
(0.64,1.46)\end{array}$ & $\begin{array}{c}1.87 \\
(0.86,4.08)\end{array}$ & $\begin{array}{c}2.39 \\
(0.58,9.82)\end{array}$ & 0.11 & 1 & $\begin{array}{c}0.71 \\
(0.18,2.74)\end{array}$ & $\begin{array}{c}1.15 \\
(0.24,5.55)\end{array}$ & $\begin{array}{c}1.53 \\
(0.32,7.41)\end{array}$ & 0.57 \\
\hline & Multivariate HR & 1 & $\begin{array}{c}0.92 \\
(0.61,1.40) \\
\end{array}$ & $\begin{array}{c}1.76 \\
(0.80,3.86) \\
\end{array}$ & $\begin{array}{c}1.92 \\
(0.45,8.11) \\
\end{array}$ & 0.21 & 1 & $\begin{array}{c}0.73 \\
(0.18,2.91) \\
\end{array}$ & $\begin{array}{c}1.36 \\
(0.27,6.80) \\
\end{array}$ & $\begin{array}{c}1.58 \\
(0.31,8.00) \\
\end{array}$ & 0.50 \\
\hline \multirow{4}{*}{ Brain cancer } & Person-years & 1018439 & 519222 & 59011 & 13830 & . & 1172713 & 683460 & 279182 & 216546 & . \\
\hline & No. of cases & 108 & 49 & 8 & 2 & . & 37 & 21 & 14 & 9 & . \\
\hline & Age-adjusted HR & 1 & $\begin{array}{c}0.94 \\
(0.67,1.31) \\
\end{array}$ & $\begin{array}{c}1.34 \\
(0.65,2.75)\end{array}$ & $\begin{array}{c}1.42 \\
(0.35,5.80) \\
\end{array}$ & 0.54 & 1 & $\begin{array}{c}0.97 \\
(0.57,1.65) \\
\end{array}$ & $\begin{array}{c}1.54 \\
(0.83,2.86) \\
\end{array}$ & $\begin{array}{c}1.32 \\
(0.64,2.75) \\
\end{array}$ & 0.18 \\
\hline & Multivariate HR & 1 & $\begin{array}{c}0.92 \\
(0.65,1.29)\end{array}$ & $\begin{array}{c}1.28 \\
(0.62,2.64)\end{array}$ & $\begin{array}{c}1.27 \\
(0.31,5.20)\end{array}$ & 0.68 & 1 & $\begin{array}{c}0.96 \\
(0.56,1.65)\end{array}$ & $\begin{array}{c}1.51 \\
(0.81,2.80)\end{array}$ & $\begin{array}{c}1.25 \\
(0.60,2.60)\end{array}$ & 0.25 \\
\hline \multirow{4}{*}{$\begin{array}{c}\text { Non-Hodgkin } \\
\text { lymphoma }\end{array}$} & Person-years & 1017995 & 518961 & 58990 & 13828 & . & 1172618 & 683400 & 279156 & 216520 & . \\
\hline & No. of cases & 594 & 332 & 32 & 8 & . & 134 & 80 & 38 & 36 & . \\
\hline & Age-adjusted HR & 1 & $\begin{array}{c}1.13 \\
(0.99,1.29)\end{array}$ & $\begin{array}{c}0.99 \\
(0.69,1.42)\end{array}$ & $\begin{array}{c}1.07 \\
(0.53,2.15) \\
\end{array}$ & 0.41 & 1 & $\begin{array}{c}1.01 \\
(0.77,1.33) \\
\end{array}$ & $\begin{array}{c}1.20 \\
(0.84,1.73) \\
\end{array}$ & $\begin{array}{c}1.44 \\
(1.00,2.08)\end{array}$ & 0.04 \\
\hline & Multivariate HR & 1 & $\begin{array}{c}1.12 \\
(0.98,1.28)\end{array}$ & $\begin{array}{c}0.98 \\
(0.69,1.41)\end{array}$ & $\begin{array}{c}1.04 \\
(0.52,2.09) \\
\end{array}$ & 0.49 & 1 & $\begin{array}{c}1.00 \\
(0.76,1.33) \\
\end{array}$ & $\begin{array}{c}1.18 \\
(0.82,1.70)\end{array}$ & $\begin{array}{c}1.41 \\
(0.97,2.04)\end{array}$ & 0.06 \\
\hline \multirow{4}{*}{ Leukemia } & Person-years & 1018429 & 519217 & 59011 & 13832 & . & 1172711 & 683457 & 279186 & 216547 & . \\
\hline & No. of cases & 108 & 72 & 8 & 2 & . & 33 & 21 & 7 & 8 &. \\
\hline & Age-adjusted HR & 1 & $\begin{array}{c}1.39 \\
(1.03,1.87)\end{array}$ & $\begin{array}{c}1.38 \\
(0.67,2.83)\end{array}$ & $\begin{array}{c}1.34 \\
(0.33,5.43) \\
\end{array}$ & 0.10 & 1 & $\begin{array}{c}1.07 \\
(0.62,1.85)\end{array}$ & $\begin{array}{c}0.90 \\
(0.40,2.04) \\
\end{array}$ & $\begin{array}{c}1.35 \\
(0.62,2.92)\end{array}$ & 0.65 \\
\hline & Multivariate HR & 1 & $\begin{array}{c}1.37 \\
(1.02,1.86) \\
\end{array}$ & $\begin{array}{c}1.30 \\
(0.63,2.68)\end{array}$ & $\begin{array}{c}1.20 \\
(0.29,4.92) \\
\end{array}$ & 0.16 & 1 & $\begin{array}{c}1.04 \\
(0.60,1.80) \\
\end{array}$ & $\begin{array}{c}0.85 \\
(0.38,1.94) \\
\end{array}$ & $\begin{array}{c}1.38 \\
(0.63,3.02) \\
\end{array}$ & 0.66 \\
\hline \multirow{4}{*}{$\begin{array}{l}\text { Multiple } \\
\text { Myeloma }\end{array}$} & Person-years & 1018393 & 519213 & 59009 & 13832 & . & 1172726 & 683469 & 279184 & 216548 & . \\
\hline & No. of cases & 131 & 51 & 8 & 0 & . & 17 & 7 & 6 & 7 & . \\
\hline & Age-adjusted HR & 1 & $\begin{array}{c}0.82 \\
(0.59,1.14) \\
\end{array}$ & $\begin{array}{c}1.16 \\
(0.57,2.38)\end{array}$ & $\mathrm{NA}^{\mathrm{c}}$ & 0.38 & 1 & $\begin{array}{c}0.67 \\
(0.28,1.64) \\
\end{array}$ & $\begin{array}{c}1.52 \\
(0.59,3.87) \\
\end{array}$ & $\begin{array}{c}2.35 \\
(0.97,5.69) \\
\end{array}$ & 0.04 \\
\hline & Multivariate HR & 1 & $\begin{array}{c}0.81 \\
(0.58,1.12) \\
\end{array}$ & $\begin{array}{c}1.13 \\
(0.55,2.33) \\
\end{array}$ & $\mathrm{NA}^{\mathrm{c}}$ & 0.34 & 1 & $\begin{array}{c}0.64 \\
(0.26,1.58) \\
\end{array}$ & $\begin{array}{c}1.50 \\
(0.58,3.85) \\
\end{array}$ & $\begin{array}{c}2.17 \\
(0.88,5.38) \\
\end{array}$ & 0.06 \\
\hline \multirow{3}{*}{ Oral cancer } & Person-years & 1018428 & 519217 & 59013 & 13831 & . & 1172729 & 683460 & 279183 & 216546 & $\dot{0}$ \\
\hline & No. of cases & 70 & 33 & 2 & 1 &. & 19 & 13 & 7 & 7 & . \\
\hline & Age-adjusted HR & 1 & 0.92 & 0.48 & 1.11 & 0.42 & 1 & 1.16 & 1.40 & 2.13 & 0.09 \\
\hline
\end{tabular}




\begin{tabular}{|c|c|c|c|c|c|c|c|c|c|c|c|}
\hline & & & $(0.61,1.40)$ & $(0.12,1.98)$ & $(0.15,8.04)$ & & & $(0.57,2.35)$ & $(0.58,3.37)$ & $(0.89,5.08)$ & \\
\hline & Multivariate HR & 1 & $\begin{array}{c}0.93 \\
(0.61,1.41) \\
\end{array}$ & $\begin{array}{c}0.51 \\
(0.12,2.08) \\
\end{array}$ & $\begin{array}{c}1.27 \\
(0.17,9.28) \\
\end{array}$ & 0.49 & 1 & $\begin{array}{c}1.11 \\
(0.55,2.28)\end{array}$ & $\begin{array}{c}1.44 \\
(0.60,3.50) \\
\end{array}$ & $\begin{array}{c}2.23 \\
(0.93,5.34) \\
\end{array}$ & 0.07 \\
\hline \multirow{4}{*}{$\begin{array}{l}\text { Other } \\
\text { cancers }\end{array}$} & Person-years & 1017856 & 518878 & 58968 & 13821 & . & 1171719 & 682784 & 278910 & 216325 & $\cdot$ \\
\hline & No. of cases & 1002 & 532 & 62 & 20 & . & 1045 & 696 & 296 & 227 & . \\
\hline & Age-adjusted HR & 1 & $\begin{array}{c}1.07 \\
(0.96,1.19) \\
\end{array}$ & $\begin{array}{c}1.10 \\
(0.85,1.43) \\
\end{array}$ & $\begin{array}{c}1.54 \\
(0.99,2.41) \\
\end{array}$ & 0.05 & 1 & $\begin{array}{c}1.15 \\
(1.04,1.26)\end{array}$ & $\begin{array}{c}1.19 \\
(1.05,1.36) \\
\end{array}$ & $\begin{array}{c}1.19 \\
(1.03,1.37)\end{array}$ & 0.003 \\
\hline & Multivariate HR & 1 & $\begin{array}{c}1.07 \\
(0.97,1.19)\end{array}$ & $\begin{array}{c}1.10 \\
(0.85,1.42)\end{array}$ & $\begin{array}{c}1.52 \\
(0.97,2.37)\end{array}$ & 0.05 & 1 & $\begin{array}{c}1.14 \\
(1.04,1.26)\end{array}$ & $\begin{array}{c}1.18 \\
(1.03,1.34)\end{array}$ & $\begin{array}{c}1.16 \\
(1.01,1.34)\end{array}$ & 0.01 \\
\hline
\end{tabular}

a Cancer sites that have more than 100 diagnosed cases in either cohort were included in the single site analyses. Cancer sites with smaller numbers of cases were grouped as other cancers;

b Multivariate models adjusted for age, smoking status (never, past, current 1-14,15-24, or 25+ cigarettes/day), alcohol intake (no, <5.0, 5.0-9.9, 10.0-19.9, or $20.0+\mathrm{g}$ /day), body mass index $\left(<25.0,25.0-29.9,30.0-34.9\right.$, or $\left.35.0+\mathrm{kg} / \mathrm{m}^{2}\right)$, physical activity $(<3.0,3.0-8.9,9.0-17.9,18.0-26.9$ or $27.0+\mathrm{metabolic}$ equivalent hours/wk), history of heart disease (yes or no), history of stroke (yes or no), history of type 2 diabetes (yes or no), history of squamous cell carcinoma (yes or no), history of basal cell carcinoma (yes or no), menopausal status/postmenopausal hormones use (premenopausal, PMH never, PMH past, or PMH current), and states lived at birth, age 15, and age 30 (UV index $<=5,=6$, or $>=7$ );

c Estimates are not available because the number of cases is zero in those exposure categories;

1 For breast cancer, we additionally included in the multivariate model duration of hormone replacement therapy use (pre-menopause, dubious menopause, post menopause age $<48$ and never user, post menopause age $<48$ and past user, post menopause age $<48$ and current user $<5$ y, post menopause age $<48$ and current user $>=5 \mathrm{y}, 48<$ post menopause age $<52$ and never user, $48<$ post menopause age $<52$ and past user, $48<$ post menopause age $<52$ and current user $<5 \mathrm{y}, 48<$ post menopause age $<52$ and current user $>=5 \mathrm{y}$, post menopause age $>=52$ and never user, post menopause age $>=52$ and past user, post menopause age $>=52$ and current user $<5$ y, post menopause age $>=52$ and current user $>=5$ y), duration of menopause (continuous variable), family history of breast cancer (yes or no), history of benign breast disease (yes or no), height $(<160.02 \mathrm{~cm}, 160.02-162.56 \mathrm{~cm}, 162.56-167.64 \mathrm{~cm},>=$ $167.64 \mathrm{~cm}$ ), weight change from age at 18 (loss $>4 \mathrm{~kg}$, stable, gain 4-10 kg, gain 10-20 kg, gain 20-40 kg, gain $>40 \mathrm{~kg}$ ), parity and age at first birth (nulliparous, parity 1-2 and age at first birth $<25$, parity $1-2$ and $25<$ age at first birth $<30$, parity $1-2$ and age at first birth $>30$, parity $3-4$ and age at first birth $<25$, parity $3-4$ and $25<$ age at first birth $<30$, parity $3-4$ and age at first birth $>30$, parity $>=5$ and age at first birth $<25$, parity $>=5$ and $25<$ age at first birth $<30)$, and age at menarche $(<=12 \mathrm{y}, 13 \mathrm{y},>=14 \mathrm{y})$;

2 For ovarian cancer and endometrial cancer, the multivariate model additionally included duration of hormone replacement therapy use, parity and age at first birth, and age at menarche, categorized as previously;

3 For melanoma, the multivariate model additionally included childhood reaction to sun (some redness or none, burn, painful burn or blisters), number of severe sunburns (none, 1-2, 3-5, 6-9, >=10), hair color (black, dark brown, light brown, blonde, red), family history of melanoma (yes or no), average time spent in sun light in summer at different age intervals $(0-2 \mathrm{hr}, 2-6 \mathrm{hr}, 6-10 \mathrm{hr},>10 \mathrm{hr})$, and cumulative UV flux (quintiles). 


\section{Cancer}

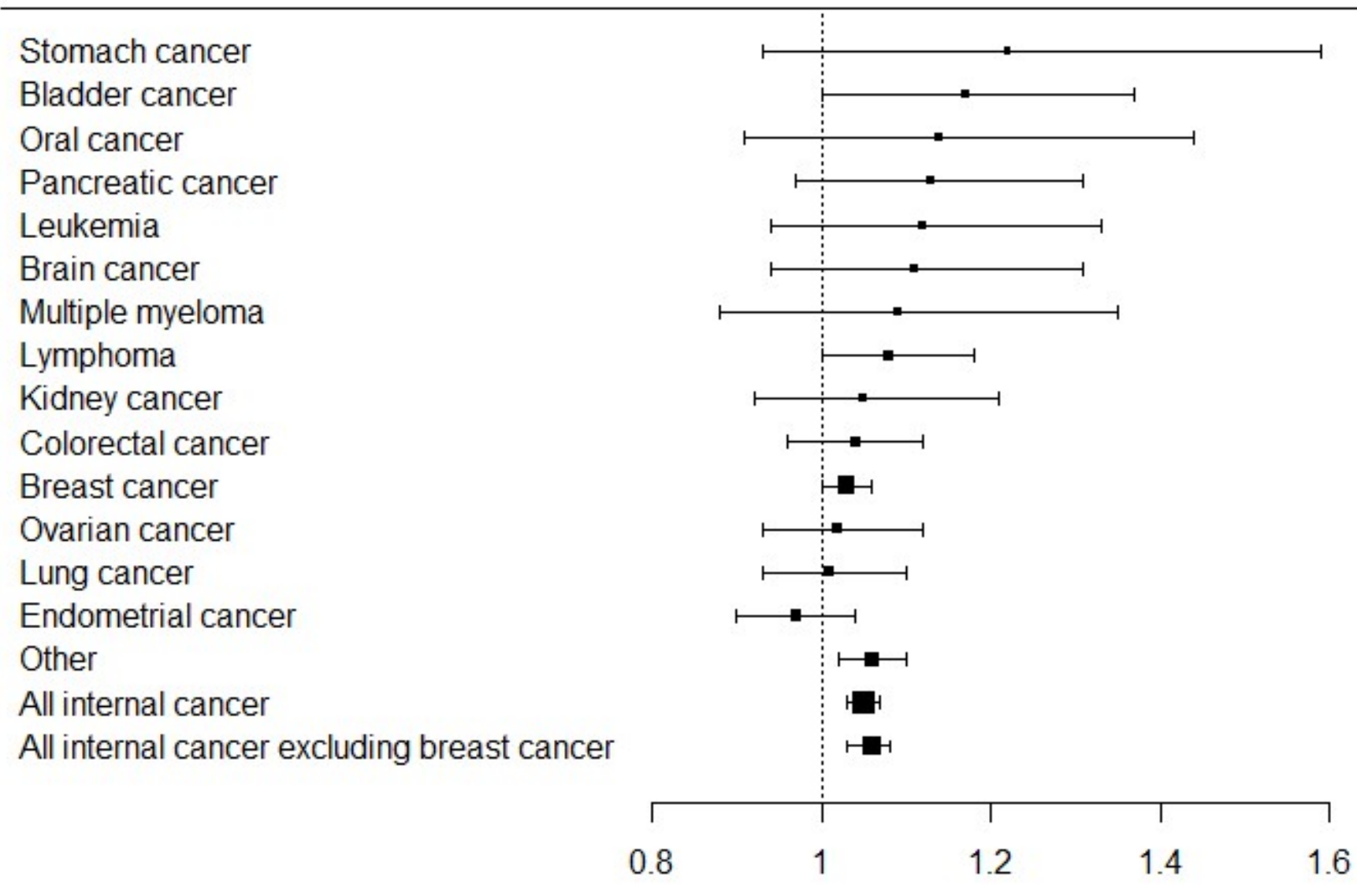

\# of Cases $\quad H R[95 \% \mathrm{Cl}]$

128

423

152

463

259

248

227

1254

418

1837

9082

974

2011

1648

3880

23004

13922
$1.22[0.93,1.59]$

$1.17[1.00,1.37]$

$1.14[0.91,1.44]$

$1.13[0.97,1.31]$

$1.12[0.94,1.33]$

$1.11[0.94,1.31]$

$1.09[0.88,1.35]$

$1.08[1.00,1.18]$

$1.05[0.92,1.21]$

$1.04[0.96,1.12]$

$1.03[1.00,1.06]$

$1.02[0.93,1.12]$

$1.01[0.93,1.10]$

$0.97[0.90,1.04]$

$1.06[1.02,1.10]$

$1.05[1.03,1.07]$

$1.06[1.03,1.08]$ 